\title{
Physician Shortage Problem in Canada from 1980 to 2015
}

\section{Shan Jiang}

School of Population and Public Health, University of British Columbia, Vancouver, Canada

*Corresponding author: Shang Jiang, School of Population and Public Health, University of British Columbia, V ancouver, Canada, T el: 1(604)3329696; E-mail: shan.jiang@ubc.ca

Received: November 24, 2016; Accepted: November 28, 2016; Published: December 22, 2016

Copyright: () 2016 Jiang S. This is an open-access article distributed under the terms of the Creative Commons Attribution License, which permits unrestricted use, distribution, and reproduction in any medium, provided the original author and source are credited.

\section{Background}

For the past two decades, Canada has been experiencing a decrease in the number of active physicians. Currently, the physician-topopulation ratio is $1: 492$, or 2.03 physicians per 1000 persons [1], in comparison to other OECD (Organization for Economic Co-operation and Development) countries, Canada has almost 1 less physician per 1000 people. This physician-to-population ratio then places Canada in the $26^{\text {th }}$ ranking position out of 34 OECD nations [1]. In the past few years, the ratio began to increase faster. In the 1970s, Canada had an abundant number of physicians to serve the population; however, from the early to mid-1980s, the federal government decided to decrease medical school admissions and available training positions to curtail active physicians who would be available to the population. Specifically, by the 1990s, a report to the Federal/Provincial/Territorial Conference of Deputy Ministers of Health recommended each province to decrease both medical school enrollment and professional training positions by $10 \%$ [1]. Also, the government has strict policies in accepting foreign doctors while they comprise about $24 \%$ of the current physician composition [1,2].

\section{What are Problems?}

There is an imbalance between total physician supply and demand. From 1980s to 2000s, the increase rate of physician number experienced a U-shaped curve. Currently the number of physicians per 1000 people is higher than before. However, it is estimated that at least 5000 more doctors are needed in active practice $[3,4]$.

The second serious shortage problem exists in rural and remote areas. According to statistics of Canadian Collaborative Centre for Physician Resources (C3PR), although more than 20\% Canadian people lives in rural areas, only less than $10 \%$ physicians choose to serve in rural areas $[1,3]$. Some provinces and territories suffer severe physician shortage. With accordance with statistics of Canadian Medical Association [3], the number of physicians per 1000 people in some provinces and territories are much lower than average level as showed in (Table 1).

Physician shortage also influences demographical distribution. The average age of physicians increases by 4.4 years during last two decades. In 2015, the average age of physicians in Canada is 50 years old [2], which means young physicians are in severe shortage.

\begin{tabular}{|c|c|c|c|c|c|c|c|c|c|c|c|c|c|c|}
\hline Year & Canada & NL & $\mathrm{PE}$ & NS & NB & QC & ON & MB & SK & $A B$ & $\mathrm{BC}$ & YT & NT & NU \\
\hline 2009 & 201 & 219 & 164 & 230 & 194 & 222 & 187 & 183 & 164 & 205 & 212 & 218 & 99 & 37 \\
\hline 2010 & 203 & 225 & 163 & 225 & 205 & 224 & 188 & 186 & 169 & 211 & 213 & 209 & 78 & 40 \\
\hline 2011 & 209 & 231 & 178 & 240 & 213 & 231 & 195 & 198 & 181 & 216 & 212 & 201 & 88 & 42 \\
\hline 2012 & 214 & 240 & 182 & 250 & 221 & 235 & 201 & 193 & 180 & 217 & 221 & 185 & 83 & 35 \\
\hline 2013 & 220 & 241 & 190 & 262 & 227 & 237 & 209 & 204 & 184 & 221 & 225 & 193 & 99 & 30 \\
\hline 2014 & 224 & 248 & 179 & 260 & 229 & 239 & 214 & 201 & 189 & 229 & 229 & 197 & 101 & 33 \\
\hline 2015 & 228 & 243 & 181 & 161 & 222 & 242 & 220 & 204 & 196 & 237 & 232 & 212 & 84 & 27 \\
\hline
\end{tabular}

Table 1: Comparison of number of Physicians per 100,000 people by province/territory [2].

Physician shortage problem causes serious results. Firstly, current physician supply cannot meet the need for medical service. In 2007, almost 1.7 million Canadians, who were above 12, reported the lack of regular physician. This amount accounts for $6.6 \%$ of Canada population. Another research points out that $14 \%$ Canadians were not able to find a family doctor in $2007[3,4]$. The second reason is that Canada is experiencing a trend of increasing proportion of seniors as other developed countries. The demand for health services is becoming greater. Current physician supply will not satisfy health service needs.

Finally, as evidence shows, increased spending on physicians, especially enlarging the number of physician, is related with a reduction in wait time $[5,6]$. In Siciliani and Hurst [7] study, the authors found an extra $\$ 100$ of per capita health expenditures (in US dollars with exchange rates adjusted for purchasing power parity) could lead to a reduction of 6.6 days in mean waiting times, or a reduction of 6.1 days in median waiting times during the time span from the time patients were listed on the wait list for surgery to the time they actually received their procedure. If physician shortage continues, the health system will suffer longer wait time and lower efficiency.

\section{What are Objectives?}

The general objective for physician human resource policy is to "attract, prepare, deploy and retain highly skilled health care providers 
to give Canadians access to appropriate, timely, effective care now and in the future" [8]. Detailed and synthesized health human resource objectives are listed as: 1) Improving health student and learner retention rates; 2) Increasing the number of residency training positions for physicians in Canada; 3) Increasing the number of internationally educated health professionals (IEHPs) integrated into the Canadian health system; and 4) Improving recruitment and retention of skilled health care providers in areas of high need, including rural and remote areas [8].

However, these objectives are conflict with governmental objective in budgetary balance. Besides, increasing number of IEHPs will undoubtedly influences Canadian graduates in job market. These conflicts will be detailed discussed in the following parts.

\section{What are Optional Policy Solutions?}

There are mainly two kinds of methods to address physician shortage problem. The first one is to raise personal workload of physicians. The second is to increase the number of physicians.

According to Staiger et al. [9], in US, physicians work 54.9 hours per week in 1996-1998. This number decreases to 51.0 hours per week in 2006-2008. At the same time, with accordance with the statistics of Canadian Medical Association, in 2010 the average work hour per week for men is 53.3 , while 48.2 for women $[3,10]$. Comparing with US physicians who are said to be very busy worldwide, the workload of Canadian physicians is almost the same. Even though the government can make physicians work harder by means of some efficiencyenhancement strategy, the improvement for current system will not be enough.

The most efficient way to address physician shortage is to increase the number of physicians. It is needed for "a pan-Canadian multistakeholder physician resource planning mechanism" [11].

Firstly, we should increase the number of students in medical schools. The decrease of medical school student number is an important reason of physician shortage. Since 1980s, federal and provincial governments began to reduce medical school enrolment and medical training programs. It was well known that Barer-Stoddart report caused federal government reduced medical school enrolment and provincially funded post-graduate training positions by 10 percent $[3,4]$. These actions resulted in an obvious reduce in physicianpopulation ratio. Currently the recruitment size is 2500 annually in Canada, while actually 3000 positions are needed [11]. The tremendous increase will satisfy medical services demand. It is also necessary to introduce more international students, which is another important source for medical school students.

Secondly, Canada should modify her strict assessment for immigrated physicians from foreign countries. Canada employed a stricter assessment for an intake of foreign physicians than local physicians after 1990s. In 1980, international medical graduates represented approximately $32 \%$ of the physician workforce and now, they only represent approximately $23 \% \quad[3,10]$. Foreign-trained physicians should undergo a standardized system to assess their credentials, professionalism, and suitability to work in the Canadian cultural environment.

Thirdly, Canada is "losing too many physicians to US" [11], and should find ways to encourage current students to practice in Canada, as well as encouraging Canadian physicians to come back. It is known that many Canadian physicians left Canada and practiced in US due to income incentives. Discussion about the reason is ongoing, and some researchers believe this might be caused by more private medical service demand and looser governmental regulation.

Fourthly, as for shortage in rural areas and some remote provinces and territories, governments should set up a series of policies to attract and encourage physicians to practice in those areas, including higher salaries, better governmental services for their families. According to CIHI report 2010, over $70 \%$ graduates choose to stay at where they receive education for career [10]. Hence, it seems difficult to attract graduates go to remote areas from big cities where medical education is much better. However, local governments in rural areas and remote provinces could financially support some students in medical schools under agreement that they have obligations to serve those areas for some years.

Finally, the retirement age for physicians in Canada is not proper. Federal government should take into account the demographical change of Canadian population and imminent aging of baby-boomer, and encourage current physicians to prolong their career after they arrive the retire age. Although this measure only has a supplemental effect for other measures, it is beneficial and provides one more choice.

The most important thing is federal government and provincial governments should take leadership in creating such a mechanism. Action is needed, as well as negotiations and collaborations.

\section{References}

1. (2012) Canadian Physician Resources - 2012 Basic Facts.

2. CIHI (2015) Supply, Distribution and Migration of Canadian Physicians, Ontario, Canada.

3. Canadian Medical Association (2012) Physician Data Centre: Canadian physician statistics.

4. Esmail N (2008) Canada's physician supply. Fraser Forum.

5. Esmail N (2003) Spending and Waiting: Canada's Dysfunctional Relationship.

6. Barua B, Esmail N (2010) Spend More, Wait Less? Fraser Forum.

7. Siciliani L, Hurst J (2003) Explaining waiting times variations for elective surgery across OECD countries. OECD, France.

8. (2011) Health Canada, Health Human Resource Strategy.

9. Staiger DO, Auerbach DI, Buerhaus PI (2010) Trends in the work hours of physicians in the United States. JAMA 303: 747-753.

10. Chan BTB (2002) From perceived surplus to perceived shortage: what happened to Canada's physician workforce in the 1990s? Canadian Institute for Health Information, Ontario, Canada.

11. Nick B (2007) Managing physician shortages: We are not doing enough. Can Med Assoc J 176: 1057-1057. 